\title{
Reliability Analysis of Key Parts of Ferris Wheel Based on ABAQUS
}

\author{
Xiang-dong $\mathrm{Li}^{\mathrm{a} 1}$, Su-qian Lian ${ }^{\mathrm{b} 2}$, Xin-dong Zhang ${ }^{\mathrm{c} 1}$, Wei Zhang ${ }^{\mathrm{d} 1}$, Min-yao \\ Huang $^{\mathrm{e} 2}$ and Zhi-rong Wang ${ }^{\mathrm{f} \text {,** }}$ \\ ${ }^{1}$ Jiangsu Province Special Equipment Safety Supervision Inspection Institute, Nanjing 210036, \\ Jiangsu, China. \\ ${ }^{2}$ College of Safety Science and Engineering, Nanjing Tech University, Nanjing 210009, Jiangsu, \\ China. \\ wangzhirong@njtech.edu.cn \\ ${ }^{*}$ Corresponding author:
}

Keywords: ABAQUS, Ferris Wheel, Safety Analysis, Support Frame, Bearing Capacity

\begin{abstract}
Ferris wheel structure with $36 \mathrm{~m}$ diameter and $40 \mathrm{~m}$ tall is analyzed with Finite Element method by using ABAQUS software in different work conditions. The finite element analysis model of Ferris wheel supporting frame is established, and the force state of the ferrule supporting frame is analyzed. The safety factor of the support frame under wind load is reduced by about one time. The degree of utilization of the carrying capacity of the support frame is discriminated. This work provides a theoretical basis for improving the design of such components and improving the safety of the key bearing components of the Ferris wheel.
\end{abstract}

\section{Introduction}

Ferris wheel, also known as the viewing car, is a large wheel-like mechanical building facilities, amusement parks, theme parks common rides, usually used as a viewing platform. According to the difference between the operating mechanisms, the Ferris wheel can be divided into gravity-type Ferris wheel and Ferris wheel [1, 2, 3, 4]. Gravity Ferris wheel cockpit is hung on the wheel to maintain the level of gravity to maintain; The view of Ferris wheel cockpit is hung outside the wheel, the need for more complex mechanical linkage structure, with the location of the car around the rotation to keep the level of adjustment. Ferris wheel is basically the main structure of the form of steel structure, its strength is directly related to the safety of passengers. The equipment needs calibration when the organization testing equipment. While ABAQUS is a mature technology of large-scale professional finite element analysis software. In this paper, the bearing strength and structural stability of a Ferris wheel are analyzed by ABAQUS.

\section{Structural Parts and the Main Performance Parameters}

In this paper, the structure of the Ferris wheel shown in Figure 1. The structure of the Ferris wheel consist of support frame, axle, rim, spoke, spoke cable and sightseeing cabin. As the support frame stand the weight of the remaining components and the rotation of the force and torque, once the support frame is out of shape, it has an important influence on the safety. The support frame of the Ferris wheel is studied as the key bearing member. This paper studies the influence of wind load on the supporting frame of Ferris wheel. The main structure of the support frame consists of six round columns with diameter of about $0.5 \mathrm{~m}$. 14 round pipe were connected between the staggered. The length of round columns is about $20 \mathrm{~m}$. The base of the column is hinged and the top is welded to the axle. Material are Q235 steel. 


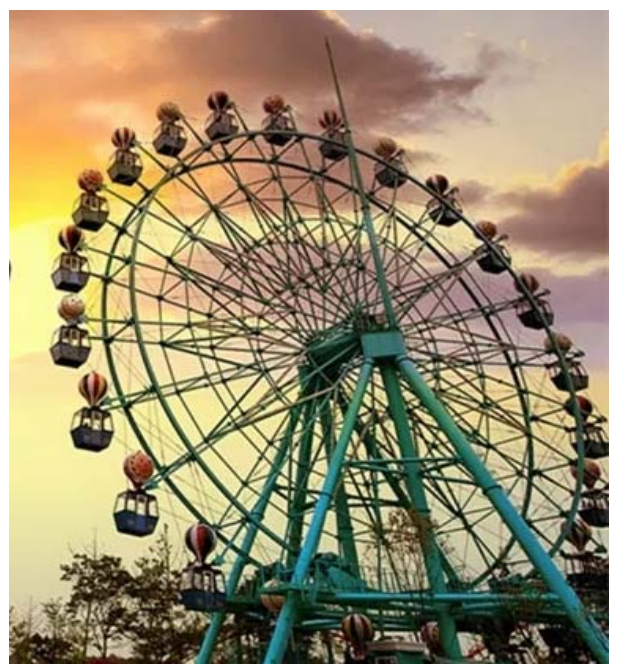

Figure 1. The View Ferris Wheel in a park in Nanjing

\section{Finite Element Model of Support Frame}

Load and operating conditions. Ferris wheel is a large high-rise equipment. The load and action of the high-rise structure has three categories: permanent load, variable load and incidental load. In this paper, the structure of the Ferris wheel static was analyzed. In this paper, the calculation load of Ferris wheel supporting frame is defined by the reference [5]. Calculation of load conditions includes self-weight and wind load.

As the Ferris wheel area of the wind is large, the device can be damaged by the wind load. The wind load need be calculated before the structure analyzed. Ferris wheel rim structure of the vertical direction is set to wind direction. The wind-static load is calculated by equivalent static force. The wind load direction is perpendicular to the surface of the Ferris wheel. The wind load shall be calculated according to the Eq. 1. [6]

$$
\omega=\beta_{z} \mu_{s} \mu_{z} \mu_{r} \omega_{0}
$$

Where $\omega$ is the wind load acting on the per unit area of the high-rise structure, $\mathrm{kN} / \mathrm{m}^{2} ; \beta_{\mathrm{z}}$ is the wind vibration coefficient at $\mathrm{z} \mathrm{m} ; \mu_{\mathrm{s}}$ is wind load shape coefficients, for round tubes $\mu_{\mathrm{s}}=0.8$; $\mu_{\mathrm{z}}$ is wind pressure height coefficient at $\mathrm{z} \mathrm{m} ; \mu_{\mathrm{r}}$ is return period adjustment coefficient; $\omega_{0}$ is basic wind pressure per area, $\mathrm{kN} / \mathrm{m}^{2}$.

Basic wind pressure shall be defined by Code Design of High-Rising Structures, shown in Equation 2.

$$
\omega_{0}=\frac{1}{2} \rho v_{0}^{2} .
$$

Where $\rho$ is air density; $v 0$ is basic wind speed.

Wind pressure height coefficient varies with the ground shape, it can be determined in Table 1[7]. Wind pressure height coefficient calculates with B ground roughness in this paper.

Table 1. Wind pressure height coefficient $\mu_{\mathrm{z}}$

\begin{tabular}{|l|l|l|l|l|}
\hline \multirow{2}{*}{$\begin{array}{l}\text { The level apart from the surface } \\
(\mathrm{m})\end{array}$} & Ground Roughness & B & C & D \\
\cline { 2 - 5 } & A & 1.00 & 0.74 & 0.62 \\
\hline 10 & 1.38 & 1.25 & 0.84 & 0.62 \\
\hline 20 & 1.63 & 1.42 & 1.00 & 0.62 \\
\hline 30 & 1.80 & 1.56 & 1.13 & 0.73 \\
\hline
\end{tabular}


Model and Methods. In view of the Ferris wheel finite element characteristics, the self-weight condition of the Ferris wheel and the no-load condition under the wind condition were simulated. Load of Ferris wheel sightseeing cabin and other parts, structural parts was computed with ABAQUS. Due to the simplification of the finite element modeling, the self-weight of the structure is reduced slightly and the weight of the structure is compensated by increasing the material density.

According to the structural characteristics of Ferris wheel and load characteristics, the support frame of this paper is modeled by beam element. Q235 steel was selected. Elastic Modulus of Q235 is $\mathrm{E}=2.10 \times 10^{5} \mathrm{MPa}$, Poisson's ratio is $\mu=0.3$, Density is $\rho=7.8^{*} 10^{3} \mathrm{~kg} / \mathrm{m}^{3}$, Gravitational acceleration is $\mathrm{g}=9.8 \mathrm{~N} / \mathrm{kg}$. The wind speed in finite element analysis is $15 \mathrm{~m} / \mathrm{s}$, and wind load is considered as a horizontal force acting in any direction. The model needs to be meshed after the model is established. The model uses a free-form model for meshing. The cell type is C3D4. The generated finite element model consists of 21116 elements. The bottom end of the support frame is fixed to the base, and the treatment is fully constrained. The support frame model is shown in Figure 2.

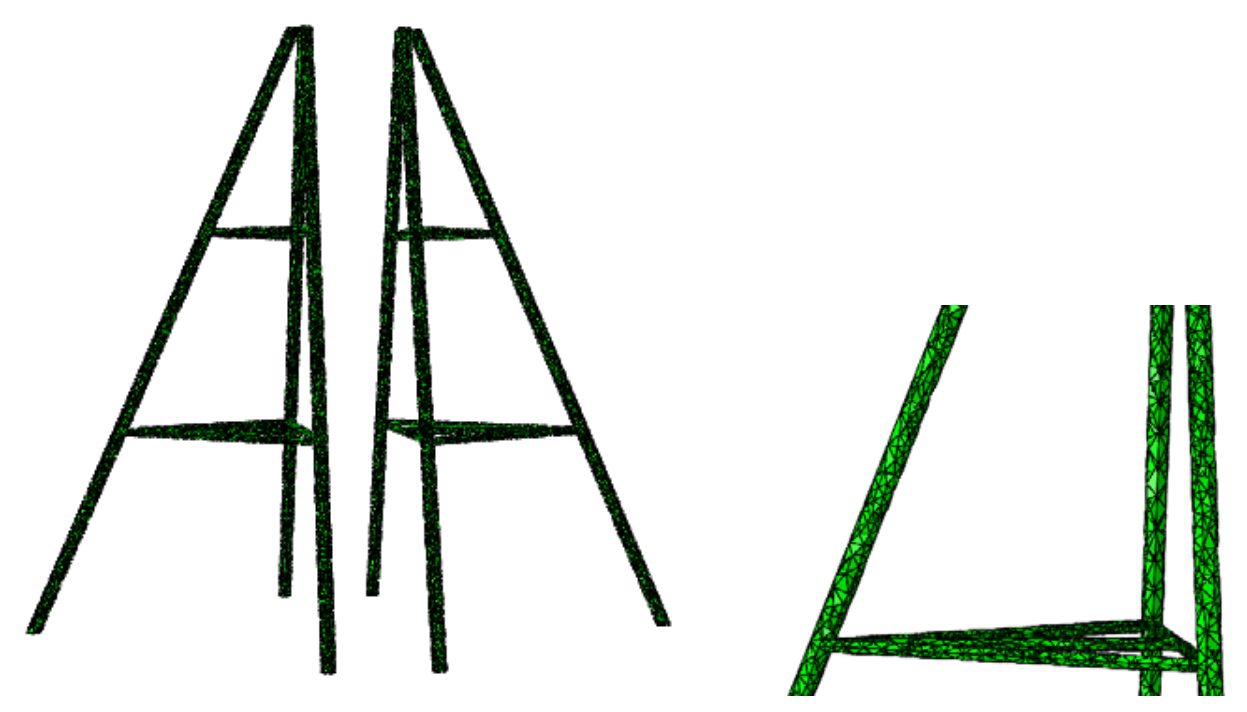

Figure 2. Finite element model of Ferris wheel supporting frame

\section{Calculation Results and Analysis}

As many units are subjected to pressure in the calculation of the support frame, and the pressure on the vertical support column is eccentric. Although the stress suffered of each unit can be directly calculated by using finite element software, but the results did not take into account the impact of factors such as load eccentricity. In this case, the maximum stress of the element obtained by calculation is less than the allowable stress, but the structure may still fail. Therefore, on the basis of the internal force calculated by the finite element method, the stability stress value under various working conditions is calculated according to the mechanics theory. The stability stress can be calculated according to Eq. 3

$$
\sigma_{\max }=\frac{N}{\varphi A}+\sigma_{M_{X}}+\sigma_{M_{y}} \leq[\sigma]
$$

Where $\mathrm{N}$ is axial pressure; $\mathrm{A}$ is sectional area of bar; $\varphi$ is axial compression bar stability coefficient; $\sigma \mathrm{My}$ is maximum stress of cross section caused by bending moment in horizontal direction at My; $\sigma \mathrm{My}$ is maximum stress of cross section caused by bending moment in vertical direction at $\mathrm{Mz}$. 
Table 2. Finite Element calculation results and analysis of support frame

\begin{tabular}{|c|c|c|c|c|}
\hline Working condition & $\begin{array}{l}\text { Maximum } \\
\text { calculated stress }\end{array}$ & $\begin{array}{l}\text { Stability } \\
\text { coefficient }\end{array}$ & Stability stress & $\begin{array}{l}\text { Allowable stress } \\
(\mathrm{Mpa})\end{array}$ \\
\hline No load (onlt gravity) & 12.3 & \multirow{2}{*}{$\begin{array}{l}\text { Slenderness ratio } \\
\text { is } 86.3, \varphi=0.73\end{array}$} & 16.85 & \multirow{2}{*}{59 (Q235 steel) } \\
\hline Wind load $(15 \mathrm{~m} / \mathrm{s})$ & 22.6 & & 30.96 & \\
\hline
\end{tabular}

When stress is calculated under wind load conditions, the largest vertical supports are located on the support brackets. The results of the finite element analysis are shown in Figure 3.

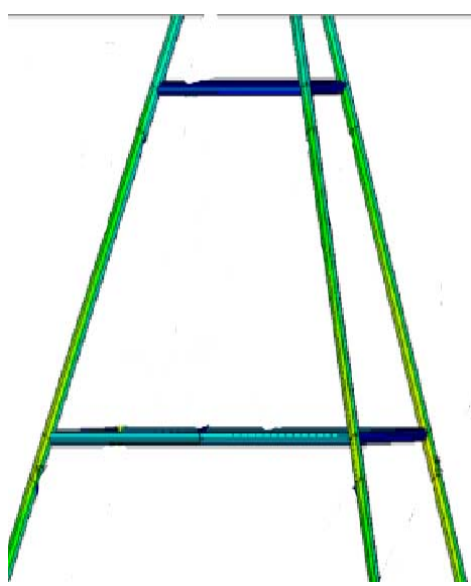

Figure 3. Results of Ferris wheel supporting frame with ABAQUS in wind load

In order to ensure that the support frame will not fail due to instability in normal operation of the most unfavorable conditions, the safety coefficient of each component is at least the required value of the allowable safety coefficient. The material of the support frame is Q235 steel. The degree of utilization of the load-bearing properties of the members is shown in the Table 3.

Table 3. Degree of bearing capacity utilization of support frame

\begin{tabular}{|l|l|l|l|}
\hline Working condition & $\begin{array}{l}\text { Permissible safety } \\
\text { coefficient }\end{array}$ & $\begin{array}{l}\text { Actual safety } \\
\text { coefficient }\end{array}$ & $\begin{array}{l}\text { Safety coefficient } \\
\text { utilization degree }\end{array}$ \\
\hline No load (onlt gravity) & \multirow{2}{*}{4} & 14.0 & $28.57 \%$ \\
\cline { 3 - 4 } Wind load $(15 \mathrm{~m} / \mathrm{s})$ & & 7.6 & $52.63 \%$ \\
\hline
\end{tabular}

\section{Conclusions}

In this paper, the finite element analysis model of Ferris wheel supporting frame is established, and the force state of the ferrule supporting frame is analyzed. The force of wind load and no-load condition are compared.

In both wind and no-load conditions, the maximum bearing capacity are in the horizontal bar at the connection.

The safety factor of the support frame under wind load is reduced by about one time. The degree of utilization of the carrying capacity of the support frame is discriminated. This work provides a theoretical basis for improving the design of such components and improving the safety of the key bearing components of the Ferris wheel.

\section{References}

[1] X. D. WANG, Y. J. Shi, Y. Q. WANG. Research on structure and engineering application of Ferris wheel. Journal of Architecture and Civil Engineering, 22(2005): 30 
[2] Z. X. Liu, Y. X. XING, H. W. Zhang, et al .GB8408-2008 Amusement device safety code. Beijing: Standards Press of China (2008)

[3] F. Zhao, J. M. Ding, H. Z. Yang, et al. Nonlinear analysis of flexible giant Ferris wheel. Journal of Tongji University (Natural science). 39(2011): 675-681

[4] A. Andrew, D. Pat, M. N. Brendon. The Singapore flyer an d design of giant observation wheels. The Arup journal, 2(2008): 2

[5] China Engineering Construction Standardization Association .GB 50009-2012 Load code for the design of building structures. Beijing: Building Industry Press of China (2012)

[6] Q. Zhang, R. B. Chen, J. X. Sun, et al. Ferris wheel structure finite element analysis and optimization design. Equipment manufacturing technology. 5(2014): 10-13

[7] Shanghai municipal construction and Transportation Commission. GB50135-2006 Code for design high-rising structures. Beijing: Plan Publishing House of China (2006) 